\title{
“Civil rights? Yeah, right!": Reflections on legislative changes from older sexual and gender minorities in Aotearoa New Zealand
}

David Betts, The University of Newcastle, Australia

\begin{abstract}
INTRODUCTION: Sexual and gender minorities continue to face social stigma and discrimination in countries that have progressively passed legislation designed to support their wellbeing and social inclusion. This article explores the impact of similar legislative changes in Aotearoa New Zealand through the reflections of older sexual and gender minorities.
\end{abstract}

METHODS: Semi-structured interviews with older sexual and gender minorities were conducted in multiple locations across Aotearoa New Zealand. Associations between legislative changes, social policy, and stigma and discrimination were examined in relation to the contemporary and historical experiences of older sexual and gender minorities.

FINDINGS: Findings indicated that changes in legislation and social policy have not protected older sexual and gender minorities from social stigma and bias, and that social workers need to be active about their role in promoting a critical awareness of these intersections.

CONCLUSIONS: With a growing number of older adults who identify as sexual and gender minorities in Aotearoa New Zealand, it is important that social workers promote a critical perspective about relying on legislation as the sole benchmark for social change.

KEYWORDS: sexual and gender minorities; older adults; legislation; social policy; social work; Aotearoa New Zealand

Aotearoa New Zealand, like many countries, has a legislative history which includes developments that have aimed to support sexual and gender diversity. Some of these key milestones in New Zealand have included the decriminalisation of homosexuality in 1986, the inclusion of sex and gender under anti-discrimination laws in 1993, and marriage equality in 2013. While these developments are successful accomplishments for wider lesbian, gay, bisexual, transgender, and queer (LGBTQ+) communities (Fenaughty \& Pega, 2016; Schmidt, 2017), there is a risk in relying on forms of legislation as the sole measure for social change. Many of these developments, such as the Homosexual Law Reform Act 1986, were not concerned with the diversity of experiences now commonly acknowledged as central to wider LGBTQ+ communities; however, these legislative changes were part of an ongoing process to build towards inclusive and supportive social policy towards all LGBTQ+ individuals. Older sexual and gender minorities are in a unique position to have experienced these changes in Aotearoa New Zealand over time, and to reflect on both how they have, and have not, impacted on their
AOTEAROA NEW ZEALAND SOCIAL WORK 32(1), 5-16.

CORRESPONDENCE TO: David Betts david.betts@newcastle.edu.au 
experiences of discrimination, stigma, and social inclusion (Van Wagenen, Driskell, \& Bradford, 2013).

Research indicates that sexual and gender minorities experience stigma, discrimination, and abuse at higher rates than heterosexual and cisgender individuals (Adams, Dickinson, \& Asiasiga, 2013; Hash \& Rogers, 2013; Mink, Lindley, \& Weinstein, 2014). For older sexual and gender minorities, there are additional, unique, challenges that their older heterosexual and cisgender peers do not face. These challenges may include being less able to rely on their biological families or families of origin, aged care services that perpetuate heteronormative attitudes, and higher rates of psychological distress resulting from exposure to social stigma (Antonelli \& Dettore, 2014; Hughes, 2009; Robinson \& Rubin, 2016). Further impacting older sexual and gender minorities is the ageism inherent in social systems and interactions (Gendon, Welleford, Inker, \& White, 2015; Hughes \& Heycox, 2010). This double jeopardy, resulting from the combination of heteronormative values with ageist attitudes, highlights the necessity of social work services that support older members of LGBTQ+ communities. Importantly, these services need to be critical about the role and limits of legislation to influence social attitudes or eradicate discrimination. The importance of this critical stance has been highlighted in Aotearoa New Zealand research that has looked at the relationship between legislative reform and social attitudes. A recent study looked at the impact of the Prostitution Reform Act 2003 which decriminalised sex work in Aotearoa New Zealand. The authors argued that, while such reforms can increase the willingness of individuals affected by legislation to engage with helping services like social workers, they do not reduce social stigma (Wahab \& Abel, 2016). The authors of this research concluded that social workers need to be aware that decriminalisation did not eradicate stigma, nor did it result in a transformation of the public perception of sex workers (Wahab \& Abel, 2016). This same reflection needs to be applied to the relationship between legislative reform and social attitudes around sexual and gender diversity in Aotearoa New Zealand.

In the data for this article, older sexual and gender minorities reflect on their experiences both prior to, and after, changes in Aotearoa New Zealand legislation. Thirty-one participants, residing in various locations across Aotearoa New Zealand, took part in this research. A process of applied thematic analysis was used to examine the participants' responses to interview questions and draw out relevant themes around legislative changes and social attitudes (Braun \& Clarke, 2006).

Within this article, the term sexual and gender minorities is used to reflect the diverse pool of people it can represent. The use of sexual and gender minorities is deliberate, intended to emphasise the fact that gender and sexuality are socio-political constructs, rather than specifically biological or natural states (Smith, Shin, \& Officer, 2011). However, when specific groups, networks, and communities that are based around identities pertaining to sexuality or gender are discussed, the term $L G B T Q+$ is used to reflect the fact that these informal and formal groups frequently self-identify with this terminology.

The findings from the analysis in this article indicated that advancements made within Aotearoa New Zealand legislation have removed the legislative risk associated with sexual and gender diversity, such as imprisonment and persecution. However, these advancements have not removed the social risks such as informal discrimination and abuse. The participants also expressed concerns that health care professionals may lack the knowledge or skills to support and respect their specific needs and experiences because of this disconnection between legislation and social change. These findings 
have specific implications for social work as they demonstrate that marginalised communities continue to face discrimination decades after the implementation of supportive and inclusive legislative acts. Social workers and other social service professionals need to be critical of attempts to minimise or ignore the concerns of LGBTQ+ communities as the experiences of older sexual and gender minorities have highlighted that this population continues to need ongoing support and advocacy.

\section{Theoretical framework}

This article draws on specific theoretical perspectives to guide the analysis and interpretation of the data. These perspectives are critical social theory and critical gerontology, both framed through a social justice agenda.

Both critical social theory and critical gerontology emphasise that social structures shape and influence individual lives (Dant, 2003; Fook, 2002; Freixas, Luque, \& Reina 2012). Specifically, these perspectives aim to highlight how social structures create barriers for wellbeing, social participation, and citizenship for minority groups. Critical social theory and critical gerontology can be used to argue that individual and community lives are influenced by cultural norms, and therefore it is important to acknowledge and critique those cultural forces (Dant, 2003; Guess, 1981). This process additionally acknowledges that power is created and controlled through forms of social interaction that create a series of privileged and oppressed roles (Fook, 2002).

Supporting this analysis of social structures was social justice. Specifically, it was the perspective that social work practice can be considered an expression of social justice (MacKinnon, 2009). Social justice is a framework that consists of political, social, and cultural objectives - which are pursued through actions and policies based on meeting basic needs and advocating for fairness and equality of treatment and social outcomes (Brown, 2006; Craig, 2002; Fook, 2002; Forrest \& Kearns, 2001). This research benefited from the application of a social justice framework, as the research design and the analysis of the data were framed through the goal of empowering and supporting the wellbeing of older sexual and gender minorities in Aotearoa New Zealand by informing social work practice, policy, and education.

\section{Materials and methods}

\section{Semi-structured interviews}

The data for this article were collected using 31 semi-structured interviews with participants. Approval for this research was provided by the University of Canterbury Human Ethics Committee in 2015.

Participants identified as sexual and gender minorities, and included: gay men, lesbian women, bisexual individuals, and transgender individuals. The interviews were conducted between the months of January and July in 2015 and took place in different urban and rural locations in Aotearoa New Zealand. The interviews lasted approximately 90 minutes. The participants were interviewed in their own homes and were recorded for transcription purposes only. The participants were ascribed pseudonyms in the transcripts and subsequent analysis to protect their anonymity.

\section{Participant demographics}

The participants were between the ages of 60 and 80 at the time of the interviews. Efforts were taken to recruit a range of participants belonging to LGBTQ+ communities, and to reflect diversity in both gender and sexual identity. The relevance of including genderdiverse individuals in this discussion around legislation such as homosexual law reform is that these developments were important milestones in later advocacy around sexual and gender diversity, which supported the implementation of anti-discrimination 
laws under the Human Rights Act 1993, and future successes such as the Marriage (Definition of Marriage) Amendment Act 2013.

Fourteen of the participants identified as male, 16 as female - three of whom were transgender women. One participant identified as intersex. Lesbian women comprised the largest group of the sample with 14 participants, gay men with 13 , bisexual individuals with three, and one participant identifying as queer. In terms of ethnicity, the largest group of participants identified as Pākehā or of European descent. A limitation of this current research comes from the lack of diversity regarding the ethnicity and background of the participants. The participants in this research primarily identified as Pākehā. While the recruitment procedures for the larger research project aimed to recruit a diverse range of older sexual and gender minorities, including specific consultation and recruitment with Māori communities, no participants reflected this demographic. As social work in Aotearoa New Zealand is guided by principles of biculturalism, specifically in support of Māori people, communities, and service provision, further exploratory research is required to address this limitation.

\section{Applied thematic analysis}

To assist in the articulation of the key themes in the data, a process of applied thematic analysis was used for the analysis in this research. Applied thematic analysis can be understood as a systematic process to distil large quantities of qualitative data to condensed and appropriate themes. This process utilised the application of codes to the transcribed interviews, where codes represented small and distinct elements of information that were pertinent to the overarching research goals. The codes were then organised and examined to display relationships and relevant connections that were then applied to the research questions to develop themes. This approach to applied thematic analysis was heavily guided by the methodology of Braun and Clarke (2006, 2013, 2014), and Guest, MacQueen, and Namey (2012).

\section{Results}

The key themes that emerged from this research originated from the fact that older sexual and gender minorities possessed a unique insight into changes in Aotearoa New Zealand legislation. More specifically, the themes focused on the impact of legislation on social views and attitudes, and how these attitudes could be reflected in the skills and competencies of helping professionals.

Throughout the interviews, the participants reflected on their experiences over time. One example was when participants talked about the process associated with the notion of 'coming out,' and how shifting laws and social policies impacted that process. One participant commented on this process, and referred to the direct impact of the Homosexual Law Reform Act 1986:

Oh, you never really come out - oh you do, you come out over a long period of time until just about everybody knows. I started when I was in my early 20s, when I was still at university ... but the main part of it followed the 1986 law. Because at that stage I was Head of Department in a large suburban co-ed school and I thought, "shit, they can know now," and so they did. People ask, "do you think you may have missed out on some promotions or opportunities because of it?" And I don't know ... I know people who did, sometimes I feel that I did. (Brian, 65)

As the participant Brian mentioned, even though it felt safer to come out in wider contexts after homosexual law reform, this did not mean the law necessarily protected sexual and gender minorities from discrimination. In the context of employment this could mean losing promotions, exclusion from workplace social environments, or 
direct abuse from colleagues. Because of the limited protection that legislation offered, not all the participants felt that the changes gave them the opportunity to be open in similar environments, including in the time directly after the law reform:

If I'd come out overtly gay when I was working in that position, I would never have been able to stay there. I would have been pushed aside. I had to stay in. (Mark, 75)

The comments by participants about their experiences coming out both before and after the Homosexual Law Reform Act 1986 highlighted the complex ways in which legislation impacted personal thoughts and reflections, as well as the lived reality of sexual and gender minorities. These findings are similar to what was found in Aotearoa New Zealand based research. A recent study explored the impact of statutory protections for people living with HIV employed in the medical workplace and found that stigma and discrimination continued to be significant issues after the implementation of this legislation (Fisher \& Henrickson, 2019). The conclusion of this research was that legislative measures alone are not enough to cease institutional discrimination, and that these efforts require additional training and mentorship to provide safe and inclusive environments (Fisher \& Henrickson, 2019). The findings from that article support what the participants in this research have stressed, which is that it is important to look beyond legislation and to continue to ascertain its weight and wider impact.

\section{Weight and wider impact}

The original Homosexual Law Reform Act 1986 contained two parts, the decriminalisation of homosexuality between two men, and anti-discrimination protection for homosexual individuals. Only the decriminalisation aspect of the Bill was passed by the New Zealand government, and it was not until the Human Rights Act 1993 that individuals were protected from discrimination based on gender and sexuality. However, there was an often-stated acknowledgment by the participants in this research that protective or inclusive legislation did not mean that discrimination and abuse were not pertinent issues for sexual and gender minorities. One participant discussed his dismay at seeing similar experiences in contemporary Aotearoa New Zealand society as to what he had experienced during the late 80 s and early 90s:

I can see so many things identical to what was happening to me when I was growing up. And here we are, the law has changed, it's all legal and everything blah blah blah, but it's a load of crap, because education hasn't come along. It hasn't come along with the legality side of it. That is the most annoying thing and it was annoying right from day one. (Dylan, 73)

The exasperation expressed by Dylan, and other participants in this research, show that it is important to be critical about the impact legislation has on social attitudes. Although some of the participants reflected on how the decriminalisation of homosexuality began to influence their own feelings of confidence and security, they often dismissed the notion that decriminalisation had a direct influence on the attitudes of wider society:

It didn't remove the social stigma, but it did remove the legislative stigma. The legal risk. I could see that having no law against it was no guarantee of it being accepted by society. (Brian, 65)

As Fenaughty and Pega have noted, in Aotearoa New Zealand the "long-standing statutory discrimination and criminalisation of men served to significantly marginalise and obscure the needs of gender- and sexually diverse minorities for many years to come" (Fenaughty \& Pega, 2016, p. 229). A participant in this research echoed that sentiment as they recounted an incident when they were the target of intense 
and public abuse during the period of decriminalisation:

My first relationship with a woman, I was in Auckland Airport one day, it was probably my first personal experience. The relationship, it was clear, was just ending and like most of us, no matter whether we're in a heterosexual or a same sex relationship, the ending of a first relationship in particular is pretty traumatic. And so we were both at the airport: I was going home and I was crying and crying and these two guys just started circling around and around just going, "Dirty dykes. Dirty dykes". (Michelle, 73)

The occurrence of public abuse such as this showed why many participants thought that the inclusion of sexuality and gender under the anti-discrimination legislation of the Human Rights Act 1993 was a key turning point for LGBTQ+ communities. This was evident when one participant described their frustration that antidiscrimination legislation was not included in 1986, and noted that it took seven years before complaints and responses concerning discrimination were legally possible:

So the second plank of the platform was that anti-discrimination ... well, which didn't come through until '93. And that's when you could start complaining on the basis of explicit discrimination, finally... (Brian, 65)

However, despite this positive development in 1993, the participants in this research expressed frustration at the slow progress that followed.

\section{A slow progression}

Frustration at the lack of social change and acceptance despite apparent legislative progress was a key theme throughout the interviews. However, this frustration was also integrated into reflections about the importance of contemporary developments in Aotearoa New Zealand legislation. The participants commented on the significance of the Civil Union Act 2004 and the Marriage (Definition of Marriage) Amendment Act 2013, with one participant discussing the resistance these forms of legislation faced from conservative politicians at the time:

Judith Collins was on quite early in the piece and she said, "so civil unions, it's just gay marriage in another form isn't it?" And I said, "no." And she said, "well how would you describe it?" And I said, "as an option that people don't have now that they really want to have." And she said, "oh, so you think people should have things just because they want them, do you?" I said, "as a matter of fact I do." And she got really wild at that point. From that point on she kept referring to this as, "this amusing submission of yours". (Tom, 70)

Another participant went on to describe the importance of the Marriage (Definition of Marriage) Amendment Act 2013 by articulating it as being intrinsically linked to the notion of equal participation in Aotearoa New Zealand society:

I think, in particular, one was very aware of being a second-class citizen. I think a lot of the arguments around marriage equality were to do with becoming a full citizen and having the full range of things that go with citizenship being available to us. And obviously looking back, that's probably why we were a lot more radical in the 70s, because there was no real likelihood that we would ever really fit in at that point. People would tolerate you and yes, most people tolerated me and accepted the fact I was gay. And I think I use the word tolerate more than full acceptance. But in those days there was really no sense that gay people would really ever fully fit in as full members of society. (Isaac, 68)

Despite the contested impact of these changes for sexual and gender minorities, 
the consensus of the participants was that these developments were important milestones in advancing the rights of LGBTQ+ communities. The participants equally reflected that the passing of the initial legislation in 1986 and 1993 were vital to the success of later developments such as civil unions and marriage equality, even if further work and advocacy was still required to dismantle forms of discrimination and stigma.

Related to these findings, there were also some interesting reflections about wider LGBTQ+ culture and community changes in the wake of legislative developments. One prominent theme described the impact legislative changes had on attitudes and relationships within community spaces:

There's been a significant change of attitude within the community in the sense that in my generation, we were forced to look after one another, because most of the gay community was behind closed doors, and we had to look after each other because the vast majority of society was not going to do that. But now it is different. The doors have opened, the windows have opened. A lot of society has opened its own closet doors. A lot of society itself has come out in different ways and I don't actually believe that law change has made a lot of difference. To a degree, it's made life safer for the gay community, but it's also changed an attitude in society in general that there's now... "everything's okay." Everything's okay. "Well, you know, you've got your freedom, you've got your human rights" - yeah right "you've got your civil liberties, so what's the problem now?" The problem is that I think to a degree the gay community is not supporting itself anymore. In one sense it doesn't need to. So there's an element of neglect. And there are some people who are just falling off the edge because of this social attitude 'well everything's alright' - and for some it isn't. (Liam, 68)
An unexpected outcome of these legislative changes is that while developments in Aotearoa New Zealand law have had only a limited influence on the day-to-day experiences of older sexual and gender minorities, these developments were having a perceived impact on community connectedness. As noted in the excerpt above, participants were worried that if there is less need, or less perceived need, then the mandate for strong social networks for older sexual and gender minorities may have been reduced. The relevance of this reflection for social workers and other helping professionals is that older sexual and gender minorities may still require those networks to support their wellbeing, particularly considering the participant reflections on the limited impact that legislative developments have had on social discrimination.

\section{Professional competencies}

An additional relevance of these findings for social work practitioners is that the participants reported contemporary experiences of discrimination resulting from reactions to their sexual or gender identities, with a common example being from medical and helping professionals. These narratives are supported by findings from previous research, where a United States study found that $13 \%$ of older sexual and gender minorities reported being denied healthcare or receiving inferior care because of their sexual and gender identity, and that up to $20 \%$ did not disclose their identity due to a fear of inferior care (Fredriksen-Goldsen et al., 2011). In Aotearoa New Zealand there has been similar research on professional attitudes and competencies. Research from 2007 that used qualitative semi-structured interviews with participants working in policy, medical, and health promotion settings found that, while the participants noted that the health care of sexually diverse individuals was an important topic, and one that was influenced by socio-political factors, there was very little mainstream policy interest on the topic in Aotearoa New Zealand (Adams, Braun, \& McCreanor, 2007). 
A lack of policy interest is likely to influence the focus and resources dedicated to sexual and gender diversity in educational programmes, which has been similarly explored in research. Research on sexuality and gender identity training within preclinical medical training in Aotearoa New Zealand has found that content on sexual and gender diversity is covered minimally, and that, while it is regarded as an important topic, finding the time and resources to appropriately address this content was a challenge for educators (Taylor, Rapsey, \& Treharne, 2018). This potential lack of content in professional training programmes was reflected in the comments of one participant in this research who noted that an absence of skills or knowledge in professionals was not necessarily a result of individual bias or beliefs. Rather, it could represent the reality of how training organisations and institutions operate:

When we say that professionals in this field are not very skilled, it's not because they don't want to be - it's because the issue hasn't been addressed. Now, I work very closely with an organisation in Australia ... and the research that's coming out of Australia is that our community, our rainbow community, is somewhere between 12 and $15 \%$ of the general population. So if you think $12 \%$, $15 \%$ of the population is not being well looked after by the caring professions and I'll sort of open that up to doctors, mental health workers, social workers, everybody - yeah, we're talking about a huge number of people. (Rowan, 62)

For the participants in this research, experiences of discrimination from healthcare and social services served as a reminder that, despite the changes in Aotearoa New Zealand legislation, professional attitudes and biases are not necessarily changing or updating. For instance, one participant talked about his encounter with a new doctor after he disclosed his sexuality, and how it altered his perspective on who should be providing his care:
The doctor in this small town said, "Well, you're not going to carry on with these practices here, are you?" I think that sort of influenced me to say, "Well, actually I really do want to have a gay doctor so that this doesn't happen". (Mark, 75)

Not all the participants focused on explicit instances of discrimination or stigma resulting from interactions with professional services. It was equally common for the participants to talk about the dismissive nature of practitioners when it came to sexual or gender identity. The notion that practitioners might adopt a position of social neutrality in their engagement with sexual and gender minorities is concerning, as it means any form of social or cultural discrimination is not considered in professional interactions. This lack of critical consideration poses the risk of further excluding or disadvantaging minority groups by not appropriately responding to their concerns or previous negative experiences. For social workers, culturally competent practice requires an acknowledgement of how sexual and gender diversity may intersect with an individual's personal experiences (Van Den Bergh \& Crisp, 2004), and this same critical stance needs to be applied to all helping professionals.

As discussed earlier, stigma, discrimination, and abuse have commonly been directed at sexual and gender minorities (Adams et al., 2013; Brennan-Ing, Seidel, Larson, \& Karprak, 2014), and this was reflected in these participants' experiences. For practitioners who focus on wellbeing, psychological distress, or day-to-day health, it is important to be mindful of all contextual factors that influence wellbeing. For older members of LGBTQ+ communities their sexual and gender diversity can potentially be central components of their sense of self, identity, and how they form important social connections (Hughes \& Heycox, 2010). As a result, one participant discussed the need to change doctors when they were not 
considerate of the relevance or importance of their sexual identity:

I've had doctors who, yeah, definitely I've had to change because they've been very much ... just dismissive of it more than anything, I think. Like not seeing it as an important part of me, of who I am. That it's not something that they want to put into the conversation - where my doctor now, very much it would be part of the conversation, where some it's like, "oh no, that's not important, you know that's not..." where actually your lifestyle and who you are is important to whatever you're talking to your doctor about. (Alison, 60)

This same sentiment is important for social workers to be mindful of, as social workers often find themselves working in the intersections between people's identity, wellbeing, and social positioning.

\section{Discussion}

One of the key implications of this research is the importance of recognising the impact of heteronormative and homophobic social structures on older adults. As part of recognising these systems, it is necessary to acknowledge the challenge of reducing their impact, either through legislative changes or professional and practice strategies. For example, changes in Aotearoa New Zealand legislation regarding sexual expression and anti-discrimination laws had only a partial impact on the day-to-day experiences of sexual and gender minorities at the time. While the participants in this research identified general improvements in perceived feelings of safety and security, shifts and changes in social attitudes were significantly slower. These systems are not static forces, and the term "historical" in the context of heteronormativity and ageism is misleading. It is naïve to assume to assume that legislative and social policy changes will automatically improve the lived experiences of older sexual and gender minorities, and that needs to be considered when social workers engage with older sexual and gender minorities.

Related to this acknowledgment of the complex relationship between legislation and social policy is the impact of these collective social shifts on professional knowledge and competencies. A lack of professional knowledge or skills is not necessarily the result of individual bias, rather it can reflect the reality of how educational programmes prepare students to work alongside sexual and gender minorities. While there are many influencing factors on how social workers may be trained to support older sexual and gender minorities (including individual student factors, the specific culture of the student cohort, and the complexity of how the stated course curriculum intersects with both the taught and learned curriculum), social work education can, and should, operate as one of the primary institutions supporting this critical competency and knowledge. Social work education does provide transferable skills so that social workers can support a wide range of individuals from diverse backgrounds (Beddoe \& Maidment, 2009); however, it is equally important that specific content on the needs of sexual and gender minorities is provided, particularly due to the concerns expressed by the older sexual and gender minorities in this research.

Social work as a profession is primed to be critical of legislation as a measure for social change and social progress. Social work must maintain this critical perspective on oppression and social justice, which includes the recognition that changing the law is one piece in a complex path towards justice and equality. As part of this process, it is imperative that social workers reflect on and critique their own practice. Continual advocacy and critical engagement with disenfranchised communities is important, but unless that same critical process is applied to reflect on the social work profession then it fails to take account of the same power systems the discipline may 
inadvertently reproduce (Fabbre, 2017). Social work must adopt critical reflexive actions that aim to keep the profession accountable to the needs and observations of the communities it works alongside. A key part of this reflective process is to instil a critical alertness to assumptions that may be built into broader social contexts, such as the perspective that legislative reform has reduced forms of bigotry around sexual and gender diversity, and to emphasise a critical consideration of the nonlinear relationship between legislation and social change at all level of social work practice, training, and education (Fenaughty \& Pega, 2016).

\section{Limitations}

As noted earlier, a limitation of this research is that none of the participants identified as Māori, which, for research in Aotearoa New Zealand, is important to acknowledge as it does not reflect the experiences of tangata whenua, nor does it reflect the values of biculturalism in Aotearoa New Zealand social work practice and research. It is important that this lack of Māori viewpoints and experiences is considered when assessing the findings of this article, and that future research adequately explores this gap and acknowledges the importance of Māori perspectives. Similarly, the participant demographics reported on here primarily reflect the lived experiences of gay men and lesbian women which reduces the depth of the findings. While this research aims to present a glimpse into the experiences of older sexual and gender minorities, and not to present a comprehensive overview of all perspectives, more diversity would assist in illuminating a broader picture for analysis.

Caution should be taken when trying to assume homogenous characteristics of any community, let alone one as diverse and varied as the myriad LGBTQ+ communities. Rather, these findings should be seen as a snapshot of a certain group's experiences, one that ideally allows social work professionals to reflect on their own biases or beliefs without making assumptions about all experiences. Gaps in the demographic spread of this research can be addressed through further studies, which would allow for a more comprehensive overview and comparison. Additionally, intergenerational research would allow for a consideration of experiences across the life course, an element this research was unable to include due to its focus on older adults.

\section{Conclusion}

One of the key insights to emerge from the reflections of the participants in this research was that older sexual and gender minorities continue to have concerns regarding social stigma and discrimination. It may be easy to dismiss these concerns as historical, but their experiences present a narrative of contemporary prejudice.

As acknowledged at the beginning of this article, older sexual and gender minorities can reflect on decades of changes and developments in Aotearoa New Zealand society. This position granted a valuable insight into the dynamic, and often frustrating, way in which minority communities fight for social acceptance in our society. Additionally, their experiences interacting with social services and helping professionals suggest that many institutional practices and services need to develop their competencies and knowledge to appropriately support older members of LGBTQ+ communities.

Future research can build on these findings in a variety of ways. More culturally inclusive research is required to represent the experiences of older Māori sexual and gender minorities, and their reflections on similar social issues. This research project involved a diverse range of participants; however, it included a larger number of gay men and lesbian women over bisexual, transgender, and intersex participants. As previous research has shown that different demographics within wider LGBTQ+ communities experience different levels of social stigma, mental health complications, 
and minority stressors (Craig \& Keane, 2014; Cathey, Norwood, \& Short, 2014; Mizock, Harrison, \& Russinova, 2014), future research could benefit from focusing more explicitly on less acknowledged groups within wider LGBTQ+ communities. This approach would benefit from drawing upon an intersectional perspective that highlights intersecting experiences, insights, potential concerns, as well as resources and community strengths (Mink et al., 2014). For an Aotearoa New Zealand context it would also be useful to research the variety and depth of the content regarding sexual and gender diversity within social work education, and the self-reported skills and competencies that social workers cite as being important when supporting sexual and gender-diverse individuals.

As one respondent put it, "well, you know, you've got your freedom, you've got your human rights" - yeah right - "you've got your civil liberties, so what's the problem now?" The sarcasm heavily relayed in "yeah right" reflects a lifetime of stigma, discrimination, and abuse so callously ignored in the societal assumption that changes in laws and social policy meant that everything was perfect. Social work needs to be at the forefront of acknowledging that disconnect and needs to continue to promote critical awareness of the intersections between law, social policy, and social attitudes.

\section{Declaration of Interest}

The author declares that there are no conflicts of interest in the writing and publication of this article.

Accepted: 7 February 2020

Published: 14 April 2020

\section{References}

Adams, J., Braun, V., \& McCreanor, T. (2007). Warning voices in a policy vacuum: Professional accounts of gay men's health in Aotearoa New Zealand. Social Policy Journal of New Zealand, 30, 199-215.
Adams, J., Dickinson, P., \& Asiasiga, L. (2013). Mental health promotion for gay, lesbian, bisexual, transgender and intersex New Zealanders. Journal of Primary Health Care, 5(2), 105-113.

Antonelli, P., \& Dettore, D. (2014). Relationship, social, and individual well-being in Italian male same-sex couples. Journal of Gay \& Lesbian Social Services, 26(3), 383-406. doi:10.1080/10538720.2014.926231

Beddoe, L., \& Maidment, J. (2009). Mapping knowledge for social work practice: Critical intersections. Melbourne, Australia: Cengage Learning.

Braun, V., \& Clarke, V. (2006). Using thematic analysis in psychology. Qualitative Research in Psychology, 3, 77-101. doi:10.1191/1478088706qp063oa

Braun, V., \& Clarke, V. (2013). Successful qualitative research: A practical guide for beginners. London, UK: SAGE.

Braun, V., \& Clarke, V. (2014). What can "thematic analysis" offer health and wellbeing researchers? International Journal of Qualitative Studies on Health and Well-being, 9(1). doi:10.3402/qhwv9.26152

Brennan-Ing, M., Seidel, L., Larson, B. \& Karprak, S. E. (2014). Social care networks and older LGBT adults: Challenges for the future. Journal of Homosexuality, 61(1), 21-52. doi:10.1080/00918369.2013.835235

Brown, K. (2006). Vulnerable adults and community care. Exeter, UK: Learning Matters.

Cathey, A. J., Norwood, W. D., \& Short, M. B. (2014). Social pain and social anxiety: Examining the experiences of ethnic, sexual, and dual minority groups. Journal of Gay \& Lesbian Mental Health, 18(3), 247-265. doi:10.1177/0361684316635529

Craig, G. (2002). Poverty, social work and social justice. British Journal of Social Work, 32(2), 669-682. Retrieved from https://www.jstor.org/stable/23716487

Craig, S. L., \& Keane, G. K. (2014). The mental health of multiethnic lesbian and bisexual adolescent females: The role of self-efficacy, stress and behavioural risks. Journal of Gay \& Lesbian Mental Health, 18(3), 266-283. doi:10.1080/19359705.2013.879846

Dant, T. (2003). Critical social theory: Culture, society and critique. London, UK: Sage Publications.

Fabbre, V. (2017). Queer aging: Implications for social work practice with lesbian, gay, bisexual, transgender, and queer older adults. Social Work, 62(1), 73-76. doi. org/10.1093/sw/sww076

Fenaughty, J., \& Pega, F. (2016). Why marriage equality is not enough: Enduring social policy concerns for gender- and sexually diverse New Zealanders. In L. Beddoe \& J. Maidment (Eds.), Social policy for social work and human services in Aotearoa New Zealand: Diverse perspectives (pp. 223-236). Christchurch, NZ: Canterbury University Press.

Fisher, M., \& Henrickson, M. (2019). Are statutory protections sufficient to protect people living with HIV who are employed in the medical workplace? International Journal of Healthcare Management, 12(1), 75-80. doi:10 $.1080 / 20479700.2017 .1398387$

Fook, J. (2002). Social work: critical theory and practice. London, UK: Sage Publications.

Forrest, R., \& Kearns, A. (2001). Social cohesion, social capital and the neighbourhood. Urban Studies, 38(12), 2125-2143. doi:10.1080/00420980120087081 
Fredriksen-Goldsen, K. I., Kim, H., Emlet, C. A., Muraco, A., Erosheva, E. A., Hoy-Ellis, C. P., Goldsen, J., \& Petry, $\mathrm{H}$. (2011). The aging and health report: Disparities and resilience among lesbian, gay, bisexual, and transgender older adults. Retrieved from http://caringandaging.org/ wordpress/wp-content/uploads/2011/05/Full-ReportFINAL-11-16-11.pdf

Freixas, A., Luque, B., \& Reina, A. (2012). Critical feminist gerontology: In the back rooms of research. Journal of Women \& Aging, 24(1), 44-58. doi:10.1080/08952841. 2012.638891

Gendon, T. L., Welleford, E. A., Inker, J., \& White, J. T. (2015). The language of ageism: Why we need to use words carefully. The Gerontologist, 55(6), 997-1006. doi:10.1093/geront/gnv066

Guess, R. (1981). The idea of a critical theory: Habermas and the Frankfurt school. London, UK: Cambridge University Press.

Guest, G., MacQueen, K. M., \& Namey, E. E. (2012). Applied thematic analysis. Los Angeles, CA: Sage Publications.

Hash, K. M., \& Rogers, A. (2013). Clinical practice with older LGBT clients: Overcoming lifelong stigma through strength and resilience. Clinical Social Work Journal, 41(3), 249-257. doi:10.1007/s10615-013-0437-2

Hughes, M. (2009). Lesbian and gay people's concerns about ageing and accessing services. Australian Social Work, 62(2), 186-201. doi:10.1080/03124070902748878

Hughes, M., \& Heycox, K. (2010). Older people, ageing and social work: Knowledge for practice. Crow's Nest, NSW, Australia: Allen \& Unwin.

MacKinnon, S. T. (2009). Social work intellectuals in the twenty-first century: Critical social theory, critical social work and public engagement. Social Work Education: The International Journal, 28(5), 512-527. doi:10.1080/02615470802406494

Mink, M. D., Lindley, L. L., \& Weinstein, A. A. (2014). Stress, stigma, and sexual minority status: The intersectional ecology model of LGBTQ health. Journal of Gay \& Lesbian Social Services, 26(4), 502-521. doi:10.1080/10 538720.2014 .953660

Mizock, L., Harrison, K., \& Russinova, Z. (2014). Lesbian, gay, and transgender individuals with mental illness: Narratives of the acceptance process. Journal of Gay \& Lesbian Mental Health, 18(3), 320-341. doi:10.1080/193 59705.2013.828007

Robinson, J. L., \& Rubin, L. J. (2016). Homonegative microaggressions and posttraumatic stress symptoms. Journal of Gay \& Lesbian Mental Health, 20(1), 57-69. doi:10.1080/19359705.2015.1066729

Schmidt, J. (2017). Homosexuality in Aotearoa New Zealand: Regulation and resistance. In A. Bell, V. Elizabeth, T. McIntosh, \& M. Wynyard (Eds.), A land of milk and honey? Making sense of Aotearoa New Zealand. Auckland, NZ: Auckland University Press.

Smith L. C., Shin., R. Q., \& Officer, L. M. (2011). Moving counselling forward on LGB and transgender issues: Speaking queerly on discourses and microaggressions. The Counselling Psychologist, 40(3), 385-408. doi:10.1177/0011000011403165

Taylor, O., Rapsey, C. M., \& Treharne, G. J. (2018). Sexuality and gender identity teaching within preclinical medical training in New Zealand: content, attitudes and barriers. The New Zealand Medical Journal, 131(1477), 35-44.

Van Den Bergh, N., \& Crisp, C. (2004). Defining culturally competent practice with sexual minorities: Implications for social work education and practice. Journal of Social Work Education, 40(2), 37-41. https://doi.org/10.1080/10 437797.2004.10778491

Van Wagenen, A., Driskell, J., \& Bradford, J. (2013). "I'm still raring to go": Successful aging among lesbian, gay, bisexual, and transgender older adults. Journal of Aging Studies, 27(1), 1-14.

Wahab, S., \& Abel, G. (2016). The Prostitution Reform Act (2003) and social work in Aotearoa/New Zealand. Journal of Women and Social Work, 31(4), 418-433. doi:10.1177/0886109916647764 